\title{
IMPLEMENTASI WARNA PADA SAMPUL BUKU CERITA BERGAMBAR LEGENDA CIUJUNG DAN CIBERANG
}

\author{
Nurdini, Winny Gunarti Widya Wardani, Febrianto Saptodewo \\ Program Studi Desain Komunikasi Visual \\ Fakultas Bahasa dan Seni Universitas Indraprasta Jakarta PGRI \\ Jl. Nangka 58 Tanjung Barat, Jakarta Selatan, 12530 \\ Nurdinie0804@gmail.com
}

\begin{abstract}
Abstrak
Legenda Ciujung dan Ciberang dapat dirancang dalam media buku cerita bergambar yang nantinya dapat dibaca oleh anak-anak. Untuk menarik minat anak-anak pada buku cerita bergambar, diperlukannya sampul buku dengan pemilihan warna yang sesuai untuk anak-anak. Adapun rumusan masalah dari penelitian ini adalah bagaimana mengimplementasikan warna pada sampul buku cerita bergambar Legenda Ciujung dan Ciberang. Penelitian ini dimaksudkan untuk memberikan informasi dan pengetahuan dalam implementasi warna pada sampul buku cerita bergambar Legenda Ciujung dan Ciberang. Metode yang digunakan dalam penelitian ini metode kualitatif deskriptif dengan pendekatan psikologi warna atau kelompok warna. Data-data yang didapat dari hasil pencarian dan pengumpulan studi literatur berupa buku-buku, skripsi, naskah arsip, wawancara dan observasi atau pengamatan langsung ke toko buku. Hasil yang didapat untuk implementasi warna sampul pada buku cerita bergambar Legenda Ciujung dan Ciberang lebih banyak memakai warna dominan yakni warna hijau, warna cokelat dan warna putih. Dimana warna-warna tersebut sesuai dengan setting atau latar cerita yang mengkondisikan daerah yang penuh dengan hutan bambu.
\end{abstract}

Kata Kunci: Sampul, Warna, Legenda, Ciujung, Ciberang

\begin{abstract}
The Ciujung and Ciberang legends can be designed in pictorial storybook media that children can later read. To attract the interest of children in illustrated story books, a book cover is needed with the right color selection for children. The formulation of the problem from this research is how to implement the colors on the cover of the story book illustrated by Ciujung and Ciberang Legends. This study is intended to provide information and knowledge in the implementation of colors on the cover of story books illustrated by Ciujung and Ciberang Legends. The method used in this study is descriptive qualitative method with a color psychology approach or color group. The data obtained from the search results and collection of literature studies in the form of books, theses, archival texts, interviews and observations or observations directly to the bookstore. The results obtained for the implementation of the color of the cover in the picture book legend Ciujung and Ciberang use more dominant colors, namely green, brown and white. Where the colors are in accordance with the setting or background story that conditions the area full of bamboo forests
\end{abstract}

Keywords: Cover, Color, Legends, Ciujung, Ciberang

\section{PENDAHULUAN}

Legenda Ciujung dan Ciberang merupakan cerita rakyat dari Banten yang diceritakan secara turun temurun sebagai pewarisan identitas kebudayaan masyarakat Banten. Legenda 
Ciujung dan Ciberang merupakan legenda yang menjelaskan bagaimana terciptanya nama Rangkasbitung (Buya Ast dan Noormansyah, 1993: 5).

Ada beberapa versi cerita Legenda Ciujung dan Ciberang namun pada dasarnya ceritacerita yang ada tidak jauh berbeda dan sama-sama mengemukakan riwayat penamaan Rangkasbitung. Rangkasbitung adalah Ibukota Kabupaten Lebak, Banten. Rangkasbitung sendiri memiliki banyak obyek wisata, sejarah, dan cerita rakyat yang tersimpan sehingga banyak wisatawan yang tertarik berkunjung ke kota ini dan mengetahui sejarah, serta budayanya (Purbaya, 1994: 6).

Menariknya, selain mengemukakan asal mula nama Rangkasbitung, Legenda Ciujung dan Ciberang juga mengandung nilai budaya yang kental dengan budaya Banten. Tidak hanya itu, ada pula pengenalan dua nama sungai yang ada di Rangkasbitung, yakni Sungai Ciujung dan Sungai Ciberang.

Legenda Ciujung dan Ciberang memiliki unsur riwayat penamaan kota Rangkasbitung, saat ini masih banyak masyarakat setempat dan anak muda di daerahnya yang tidak mengetahui makna dan sejarah dibalik penamaan daerahnya. Sebagaimana diketahui pada suatu daerah diberi nama karena adanya peristiwa-peristiwa yang terjadi pada masyarakat setempat dan tidak terlepas dari cerita yang berkembang di masyarakat. Untuk itu, Legenda Ciujung dan Ciberang dapat dirancang dalam media buku cerita bergambar yang nantinya dapat dibaca oleh anak-anak.

Namun, untuk menarik minat anak-anak pada buku cerita bergambar, diperlukannya sampul buku dengan pemilihan warna yang sesuai untuk anak-anak. Sebagaimana kita ketahui warna dapat menambah keefektifan penyampaian pesan kepada audience. Menurut Hartoko (2010: 139), cover buku merupakan salah satu unsur standar yang dipakai untuk menentukan dalam menarik minat pembaca untuk membeli buku tersebut sehingga desain cover buku begitu penting.

Menurut Darmawapira (dalam Sidhartani, 2015: 85) pilihan seseorang terhadap warna bisa juga berbeda-beda, hal ini karena biasanya selera orang tersebut dipengaruhi oleh faktor pengalaman pribadi terhadap warna-warna tertentu. Dengan demikian dapat dikatakan bahwa penggunaan warna-warna tertentu akan mempengaruhi persepsi dan pengamatan sesuai dengan pengalaman dan pemahaman pribadi yang dimilikinya, di mana hal ini tidak lepas dari pemahaman menurut asosiasi umum yang telah disepakati. Sementara, Sadjiman Ebdi Sanyoto (2005: 9) mendefinisikan warna secara fisik dan psikologis. Warna secara fisik adalah sifat pencahayaan yang dipancarkan, sementara warna secara psikologis sebagai bagian dari pengalaman indera penglihatan.

Adapun rumusan masalah dari penelitian ini adalah bagaimana mengimplementasikan warna pada sampul buku cerita bergambar Legenda Ciujung dan Ciberang. Penelitian ini dimaksudkan untuk memberikan informasi dan pengetahuan dalam implementasi warna pada sampul buku cerita bergambar Legenda Ciujung dan Ciberang.

\section{METODE PENELITIAN}

Metode yang digunakan dalam penelitian ini menggunakan metode deskriptif, metode ini memaparkan bagaimana menerapkan warna pada sampul buku cerita bergambar Legenda Ciujung dan Ciberang yang dikhususkan untuk anak-anak. Data-data yang didapat merupakan hasil dari pencarian dan pengumpulan studi literatur dari buku-buku, jurnal, wawancara dan observasi, serta pengamatan langsung ke toko buku dan ke tempat objek dari Legenda Ciujung dan Ciberang.

\section{PEMBAHASAN \\ Perancangan Cover}

Cover merupakan salah satu bagian luar dari buku yang terdiri dari judul buku, nama pengarang, nama penerbit dan gambar yang mewakili isi. Kemudian, adapula kulit buku dan bagian belakang yang terdiri dari sinopsis isi buku/ulasan isi buku, ISBN, alamat penerbit dan ada juga yang mencantumkan biografi penulis. 
Cover buku juga dapat diartikan sebagai bagian terluar dari buku (disebut juga sebagai kulit buku) yang terdiri dari bagian depan (front cover) dan bagian belakang (back cover) (Wibawa, 2013: 2). Untuk itu, dalam hal ini diperlukannya desain cover yang baik pada sebuah buku adalah agar buku tersebut memiliki nilai jual yang tinggi sehingga dalam perancangannya menjadi terlihat menarik. Sampul buku cerita bergambar Legenda Ciujung dan Ciberang menggunakan warna-warna yang dominan dan dapat dikatakan tidak banyak memakai banyak warna. Sampul buku ini juga menggunakan ilustrasi dari karakter tokoh Pakujung, Nyi Putri, dan Si Berang dengan gaya kartun sehingga dapat menarik perhatian si pembaca, yakni anak-anak.

\section{Warna}

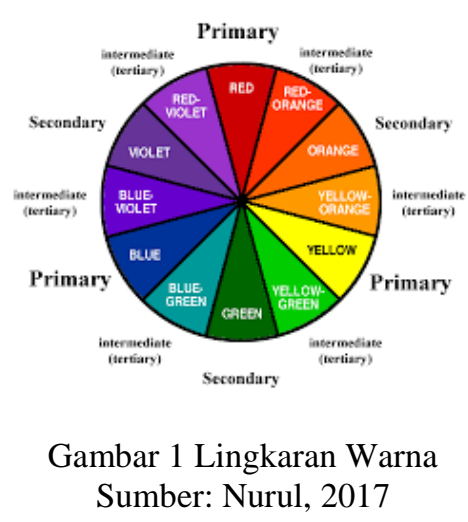

Pengenalan warna bermanfaat untuk meningkatkan daya pikir dan kreativitas anak. Selain itu, dapat meletakkan dan menanamkan dasar-dasar pengetahuan yang lebih mudah kepada anak, agar anak bisa lebih gampang menerimanya. Salah satunya dengan mengenalkan warna. Menurut Sahar (2014: 3), aktivitas mengenalkan warna juga dapat mendorong anak membuat suatu inovasi besar, kepekaan anak akan meningkat terhadap suatu objek yang dilihatnya, sehingga anak juga mampu membedakan dan menganalisanya.

Menurut Brewster (dalam Ali Nugraha, 2008: 35) Warna-warna yang ada di alam terbagi menjadi empat kelompok warna, yaitu warna primer, sekunder, tersier, dan netral. Berikut ulasannya.

\section{Warna Primer}

Warna primer adalah warna dasar yang tidak berasal dari campuran warna-warna lain. Warna primer yakni warna-warna dasar. Warna primer tersusun atas warna merah, kuning, dan hijau.

\section{Warna Sekunder}

Warna sekunder merupakan hasil campuran dua warna primer dengan proporsi yakni 1:1. Warna jingga merupakan hasil campuran warna merah dengan warna kuning. Warna hijau adalah campuran biru dan kuning. Warna ungu adalah campuran warna merah dan biru.

\section{Warna Tersier}

Warna tersier merupakan campuran satu warna primer dengan satu warna sekunder. Istilah warna tersier merujuk pada warna-warna netral yang dibuat dengan mencampur tiga warna primer dalam sebuah ruang warna.

\section{Warna Netral}

Warna netral adalah hasil campuran ketiga warna dasar dalam proporsi 1:1:1. Campuran menghasilkan warna putih atau warna kelabu dalam sistem warna cahaya aditif, sedangkan sistem warna yang subtraktif pada pigmen atau cat menghasilkan warna cokelat, kelabu dan hitam. 
Adapula arti makna yang berbeda-beda, berikut arti warna berdasarkan lingkup yang universal (Anggraini \& Nathalia, 2016: 38).

1. Warna hijau

Melambangkan alam, kehidupan, sehat dan natural.

2. Warna cokelat

Warna cokelat bermakna natural, kehangatan, membumi dan lebih stabil.

3. Warna putih

Warna putih bermakna yang paling terang dan melambangkan cahaya.

4. Warna biru

Melambangkan harmonis, terkesan lapang, kesetiaan, ketenangan, sensitif dan kepercayaan.

\section{Konsep Dasar Perancangan}

Konsep dasar perancangan sampul buku cerita begambar Legenda Ciujung dan Ciberang sebagai berikut.

\section{Strategi Media}

Sampul buku cerita bergambar Legenda Ciujung dan Ciberang menggunakan strategi media, sebagai berikut.

1. Target Audience

Anak-anak atau pelajar

2. Geografis

Wilayah Banten, Jabodetabek, dan Pulau Jawa.

3. Demografis

Jenis Kelamin: Laki-laki dan perempuan berusia 8-12 tahun.

4. Psikologis

Anak-anak yang suka membaca buku dan menyukai cerita rakyat.

\section{Konsep Media}

Berdasakan hasil analisa segmentasi dan targeting di atas, maka peneliti merancang konsep media buku cerita bergambar Legenda Ciujung dan Ciberang sebagai berikut.

1. Judul Buku

Judul media buku cerita bergambar yang digunakan yakni "Legenda Ciujung dan Ciberang", serta dengan anak judul cerita rakyat dari Lebak.

2. Deskripsi dan bentuk buku

Ukuran buku cergam Legenda Ciujung dan Ciberang adalah $20 \mathrm{~cm}$ x $25 \mathrm{~cm}$ dengan bentuk persegi panjang atau potrait. Untuk jenis sampul depan dan sampul belakang menggunakan jenis hard cover.

\section{Proses Perancangan Cover}

Berdasarkan konsep dasar perancangan, proses pewarnaan perancangan sampul buku cergam Legenda Ciujung dan Ciberang dibuat dengan beberapa proses berikut.

\section{Sketsa}

Adapun beberapa alternatif desain sketsa sampul buku cergam dibuat menggunakan teknik manual. 
1. Sketsa Sampul Pertama

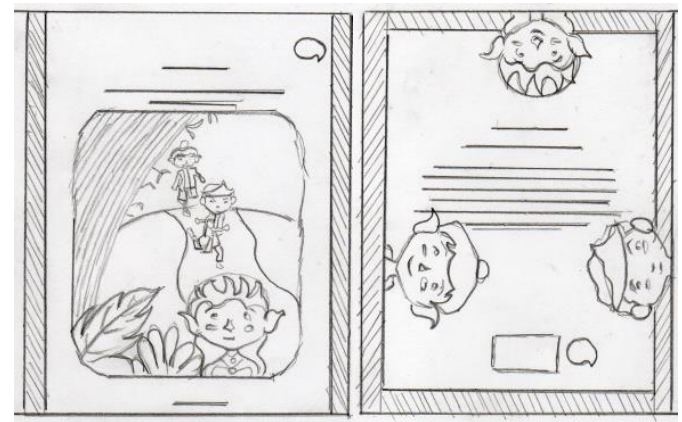

Gambar 2 Sketsa sampul 1

Sumber: Dokumentasi Pribadi

2. Sketsa Sampul Kedua

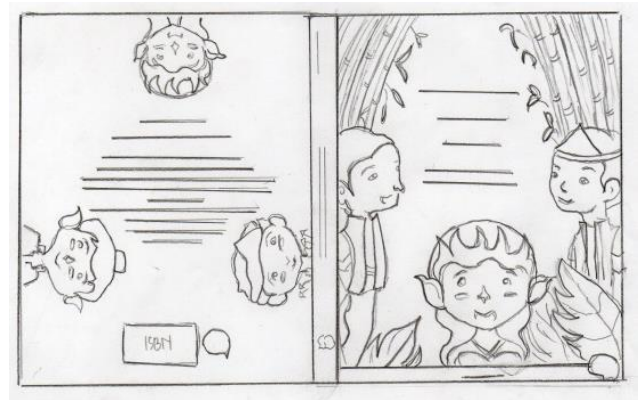

Gambar 3 Sketsa sampul 2

Sumber: Dokumentasi Pribadi

\section{Proses Pewarnaan Cover}

Setelah proses pembuatan beberapa alternatif desain sketsa sampul buku cerita bergambar Legenda Ciujung dan Ciberang. Proses selanjutnya adalah pewarnaan sampul dengan menggunakan proses pewarnaan secara digital dan menggunakan program aplikasi menggambar Paint Tools SAI, berikut beberapa alternatif desain sampul yang telah diberi warna.

1. Pewarnaan Sampul Pertama
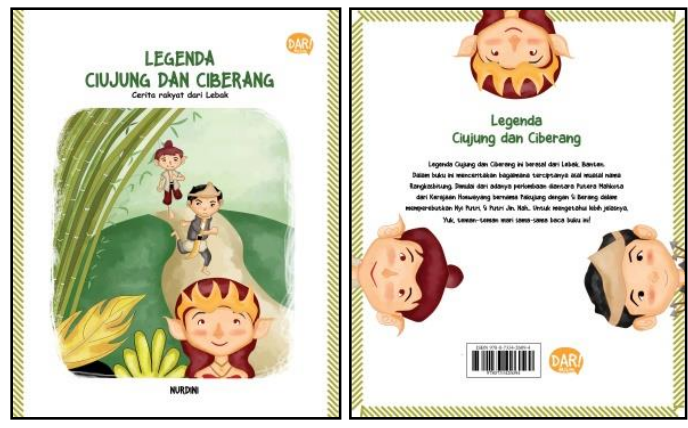

Gambar 4 Pewarnaan sampul 1 Sumber: Dokumentasi Pribadi 
2. Pewarnaan Sampul Kedua

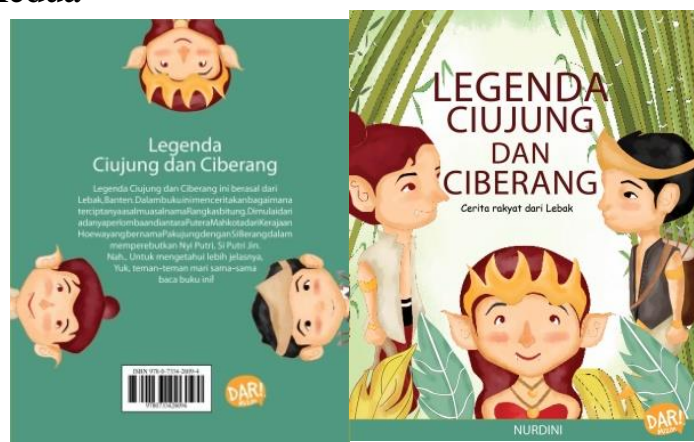

Gambar 5 Pewarnaan sampul 2

Sumber: Dokumentasi Pribadi

\section{Hasil Perancangan Cover}

Setelah tahapan sketsa dan pewarnaan, maka sampul buku cerita bergambar Legenda Ciujung dan Ciberang yang terpilih yakni desain sampul buku yang kedua. Desain sampul yang terpilih ini karena pewarnaan paling dominan dan memenuhi dengan penerapan warna utama yakni, warna hijau. Adapun desain sampul yang terpilih sebagai berikut.

\section{Desain Sampul Terpilih}

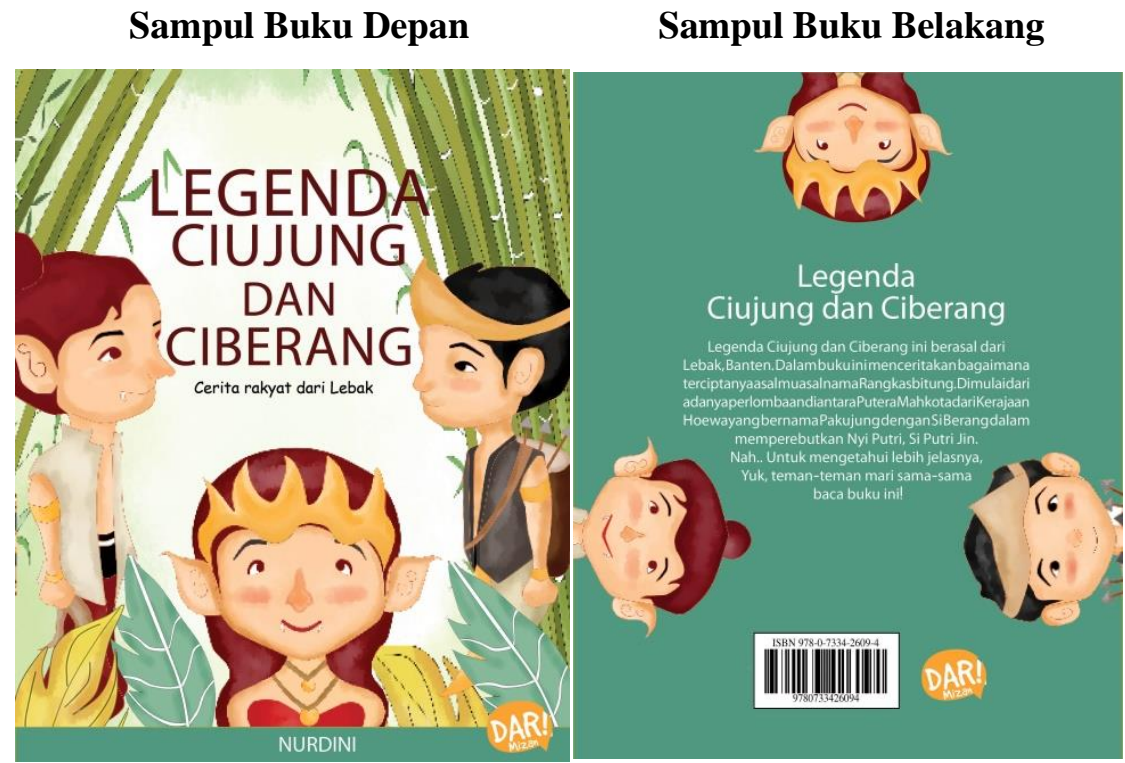

Gambar 5 Desain Sampul Terpilih

Sumber: Dokumentasi Pribadi

Desain sampul buku yang terpilih ini memiliki daya tarik tersendiri bagi para pembaca atau orang yang melihatnya. Sampul buku terpilih ini juga memiliki keterkaitan dengan isi cerita. Penerapan warna pada desain sampul yang kedua lebih menonjol dibandingkan dengan penerapan warna desain sampul pertama yang masih terlihat kurang atau kosong. Selain itu, adapula keseimbangan dengan hadirnya white space yang akan menunjukkan kesederhanaan. 


\section{Implementasi Warna}

Pada implementasi warna pada sampul buku cerita bergambar Legenda Ciujung dan Ciberang untuk usia dini, peneliti menggunakan beberapa warna dominan pada buku tersebut, warna-warna tersebut diantaranya warna hijau, warna putih, dan warna cokelat.

\section{Skema Warna}

\begin{tabular}{|c|c|}
\hline Warna & Keterangan \\
\hline & $\begin{array}{l}C: 54 \% \\
M: 17 \% \\
Y: 95 \% \\
K: 1 \%\end{array}$ \\
\hline & $\begin{array}{l}C: 71 \% \\
M: 22 \% \\
Y: 58 \% \\
K: 3 \%\end{array}$ \\
\hline & $\begin{array}{l}C: 6 \% \\
M: 18 \% \\
Y: 31 \% \\
\text { K : } 0 \%\end{array}$ \\
\hline & $\begin{array}{l}C: 34 \% \\
M: 97 \% \\
Y: 91 \% \\
K: 51 \%\end{array}$ \\
\hline & $\begin{array}{l}\mathrm{C}: 0 \% \\
\mathrm{M}: 0 \% \\
\mathrm{Y}: 0 \% \\
\mathrm{~K}: 0 \%\end{array}$ \\
\hline
\end{tabular}

Tabel 1 Skema Warna

\section{Warna Hijau}

Impelementasi warna hijau turunan lebih didominankan pada sampul buku cerita bergambar Legenda Ciujung dan Ciberang ini. Warna hijau yang digunakan warna hijau daun dan warna hijau kebiruan. Hal ini disebabkan karena warna hijau menujukan makna dari isi cerita, dimana setting atau tempat kejadian cerita yang menunjukan lebih banyak di alam, yakni di hutan penuh pepohonan bambu.

Hjiau melambangkan ciri atau mewakili dari cerita legenda Ciujung dan Ciberang. Warna hijau memiliki makna pada hijaunya alam, tumbuh-tumbuhan, sesuatu makhluk hidup. Hijau memiliki karakter atau watak segar, muda, hidup dan beberapa yang hampir sama dengan warna biru. Warna hijau juga sebagai sumber kehidupan. 


\section{Warna Cokelat}

Warna cokelat yang terdapat di sampul buku cerita bergambar ini menggunakan warna cokelat muda dan warna cokelat tua yang terlihat pada ilustrasi tokoh dan warna tulisan. Penggunaan warna cokelat menunjukan kehangatan, dan membumi. Pemakaian warna cokelat pada warna tulisan Judul buku cergam ini menjadikan tulisan mudah dibaca dan kontras saat dilihat. Pemakaian warna cokelat digunakan karena menjadi bagian cerita yang yang berlatar tempat di alam dan waktu zaman dahulu.

\section{Warna Putih}

Warna putih disini menjadi ruang kosong atau white space, dari sini maka dapat membentuk desain sampul yang mudah dibaca oleh si pembaca atau orang yang melihatnya. Warna putih memberi kesan cahaya dan kecerahan. Warna putih disini menjadi warna netral dengan dipadukan dengan warna dominan warna hijau dan warna cokelat. Perpaduan ini menimbulkan rasa nyaman dan kontras untuk sampul buku.

\section{SIMPULAN}

Implementasi warna pada sampul buku memiliki arti yang dapat dikaitkan dengan segmentasi ataupun isi dalam cerita tersebut. Terlebih lagi warna yang terdapat pada sampul seperti sampul buku cerita bergambar Legenda Ciujung dan Ciberang akan mempengaruhi minat baca, khususnya anak-anak. Pemilihan warna yang tepat dan sesuai akan menjadikan sampul buku diminati banyak orang dan si pembaca.

\section{DAFTAR PUSTAKA}

Ali, N. (2008). Pengembangan Pembelajaran Sains pada Anak Usia Dini. Bandung: JILSI Foundation.

Anggraini, S.L. \& Nathalia, K. (2016). Desain Komunikasi Visual, Dasar-dasar Panduan Untuk Pemula. Bandung: Nuansa Cendekia.

Buya, R.M. \& Noormansyah, R. (1993). Legenda Dari Jawa Barat Ciujung \& Ciberang. Jakarta: Pionir Jaya.

Hartoko, A. (2010). Jadi Desainer Andal Dengan Coreldraw. Yogyakarta: Penerbit Multico.

Nurul, M. (2017). Pengembangan Buku Panduan Menggambar Dan Mewarnai Ragam Hias Dengan Teknik Gradasi Pada Siswa Kelas V SDN Kajar 01 Pati. Universitas Negeri Semarang, Semarang.

Purbaya, J.R. (1994). Legenda dari Jawa Barat, Asal Muasal Rangkasbitung. Bandung: CV Pionir Jaya.

Santoyo, E.S. (2005). Dasar-Dasar Tata Rupa dan Desain. Yogyakarta: Jalasutra.

Sahar, S., \& Rohita, R. (2014). Meningkatkan Kemampuan Mengenal Warna Dengan Metode Eksperimen Di Kelompok Anak Usia 3-4 Tahun Di PPT FLAMBOYAN RW. II. PAUD. Teratai, 3(3), 1-6. 
Sidhartani, S. (2015). Elemen Visual Dan Prinsip Desain Sebagai Bahasa Visual Untuk Menyampaikan Rasa, Studi Kasus: Aplikasi Elemen Visual dan Prinsip Desain pada Karya Nirmana Dwimatra. Deiksis, 2(02), 82-95. 